\title{
The many versions of the painting of Tingqua's studio: painting copying and originality in nineteenth-century canton
}

\author{
Elad Yaron (1D ${ }^{1 凶}$
}

Personal expression was generally not part of the job requirements of trade-painters in nineteenth-century Canton, China. They were asked to produce paintings tailored to their Western consumers' interests, wishes, and needs. Yet, in the middle of this "art-world" lies an enigma: a set of thirteen paintings depicting the workshop of the trade-painter Tingqua, which seem, at first glance, to be duplicates of a mundane product of the industry. Closer examination, however, reveals not only that each of these versions is unique, but also that the series as a whole is actually extraordinary. The workshop paintings are full of details, including various quotes written in calligraphy, which would not have been understood either by Western or even by most Chinese viewers, but only by members of the scholar-gentry, that is, the literati of China. The main question we face before this thirteen-piece puzzle is: why did the artist plant messages or integrate codes in paintings that were sent to a world in which nobody could decode them? I propose that these workshop paintings be read as a selfportrait of a person living in a world that is witnessing a contest between two substantially different momentous cultures, each struggling to prove its superiority or dominance. Watching the demise of an old world to which he himself was contributing, Tingqua decided to treasure some of its features despite knowing that those who purchased the works would not be able to appreciate them.

\footnotetext{
${ }^{1}$ The Hebrew University of Jerusalem, Jerusalem, Israel. ${ }^{凶}$ email: EladYaron@gmail.com
} 


\section{Preface}

ere, I am offering a fresh look at thirteen paintings, ostensibly different versions of a single work depicting the workshop of the Chinese trade-painter Tingqua (Figs. 1-13). In the discussion that follows, I shall refer to them as the "workshop paintings." Today they are scattered among various museums and collections across the world, including the Metropolitan Museum of Art (New York), the Peabody Essex Museum (Salem, MA), and the Hong Kong Museum of Art. These are executed in a hybrid style rooted in both the Chinese and Western traditions. At first glance, each of the paintings looks like an ordinary artifact, a souvenir made for Western tourists and that flatters the Western "gaze." However, by analyzing them as a group and drawing comparisons between the versions, we will discover the extraordinary features that lie beneath their ordinary surface.

Over the past decades, the workshop paintings have become well known. Carl L. Crossman (1972) was one of the first to draw attention to them in his influential book The China Trade. However, though many articles refer to individual versions of the workshop paintings (e.g., Chrisman, 1984; Wing Chong, 2011; Cody and Terpak, 2011; Conner, 2013), none is devoted to the entire series. Surprisingly, most scholars dealing with the workshop paintings do not even acknowledge the existence of these numerous versions, and those that do (e.g., Conner, 1986; Lee, 2014) rarely mention the many obvious and minute differences between them.

I believe that the workshop paintings were most probably produced at the studio of the Cantonese artist known in the West as Tingqua (Guan Lianchang, 关联昌, 1809-1970s). The period to which the paintings' theme dates-the years between ca. 1850 and 1861, that is, between the two Opium Wars-marks the beginning of the transition towards modernization in Chinese history. If we also take into consideration the location of Tingqua's workshop-on New China Street near Canton's Western quarter-we can place these paintings at the center of that transition.

The workshop paintings originated in the city of Canton, a short walking distance from its Western factories. The word factory is used here in its original sense, as the premises of a factor, or merchant. From 1757 to 1842 , these warehouses were the principal and sole legal site of most Western trade with China. Between the two Opium Wars, the situation started to change. The escalation of cross-cultural tension was reflected by the increase in the amount of closed-off space around these factories. Thus a barrier was erected by the entrance to New China Street, allowing it to be closed during emergencies and at night (Farris, 2007).

Despite the limited documentation on this era, we can say that Westerners were responsible for much of the assimilation of the medium of oil painting in Canton. However, the Chinese also played a part in this process. In the mid-eighteenth century, the large porcelain factories from Jingdezhen started to send pottery to Canton where the painting on the porcelain and a second firing was done. Some scholars believe that this shift had a significant impact on the establishment of Canton's art world (Fan, 2004). We know of about thirty painting studios active in the area from 1816 to 1835 , and that by 1848 , many hundreds of hands were employed in the field (Poel, 2016).

The main products of Canton's art world were those made for export to the West. These included trade paintings. Crossman (1972) points out that as the century progressed, the quality of these works declined. Save a tiny number of painters, among whom were Tingqua and his brother Lam Qua, most of the city's artists have faded into oblivion, and were not well known even to Westerners visiting Canton back then.

Lam Qua (Guan Qiaochang, 关乔昌, 1801-1860), Tingqua's older brother and his painting teacher, focused on mastering a Western realist style to become one of Canton's most notable and possibly most Westernized artists. His name appears in nearly all

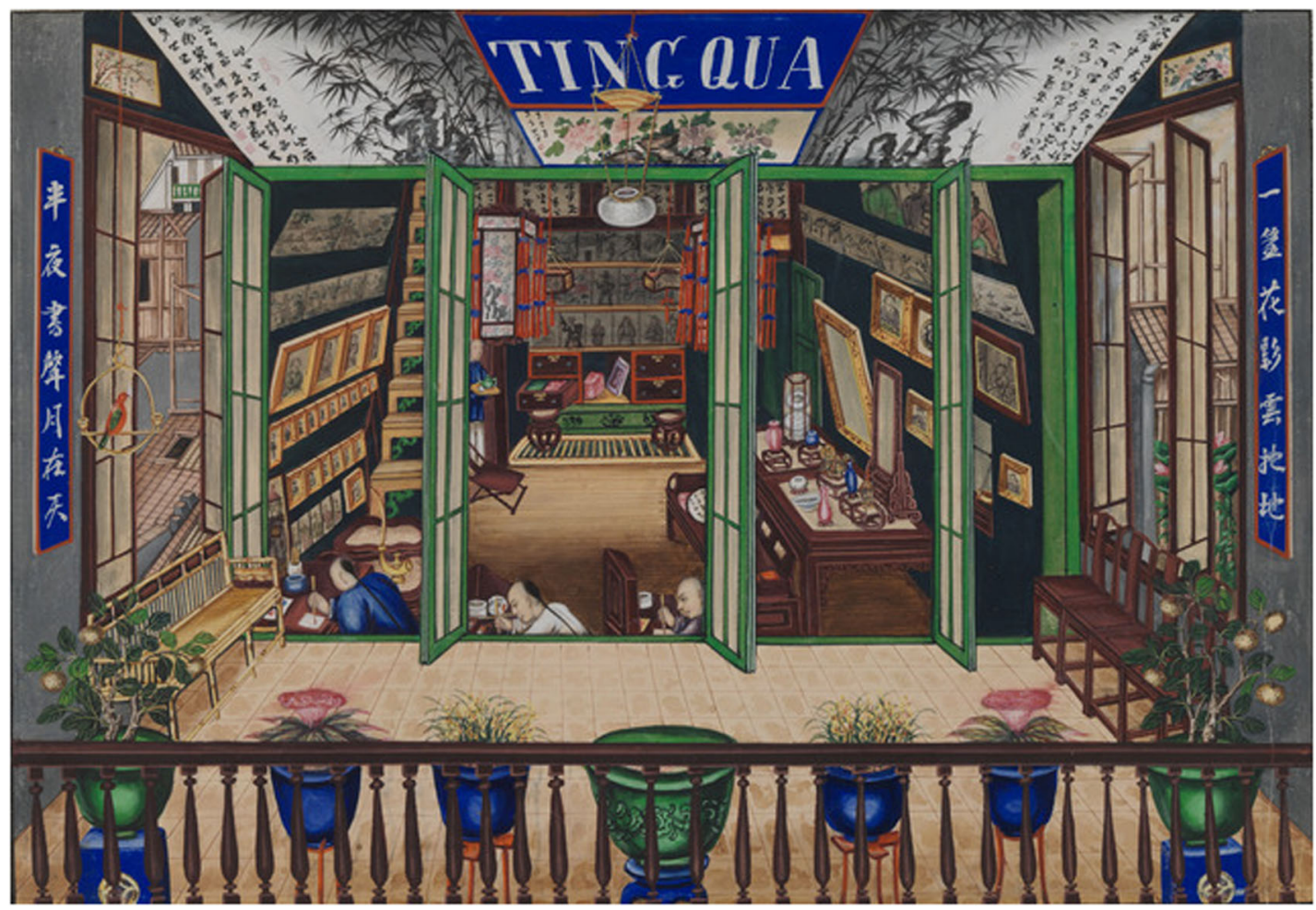

Fig. 1 Unknown artist, The Studio of Tingqua. Watercolors on paper. Peabody Museum, Massachusetts. Catalog no. AE85592. $26 \times 18 \mathrm{~cm} .1950-1961$. Provenance: Gift of Leo A. and Doris C. Hodroff, 1998. Courtesy of Peabody Essex Museum. Photo by University of Tokyo. 


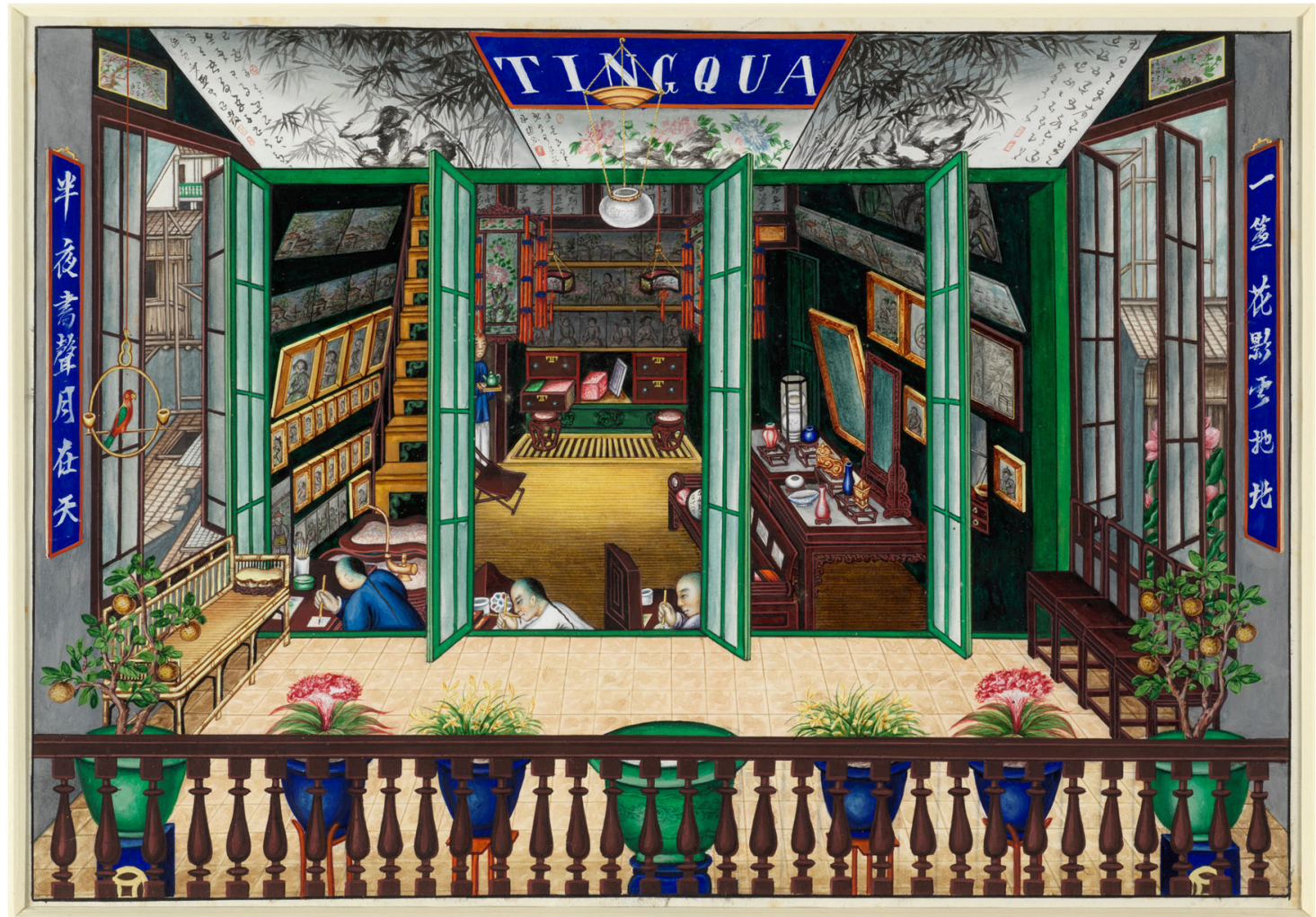

Fig. 2 Unknown artist, The Studio of Tingqua. Watercolors on paper. Christopher Sargent's collection, Washington DC. $17.9 \times 25.5 \mathrm{~cm}$. Provenance: Sold by Christie's London, 3 and 6 July 1984, and later by the Martyn Gregory Gallery, London, unknown year. Photo: Martyn Gregory Gallery.

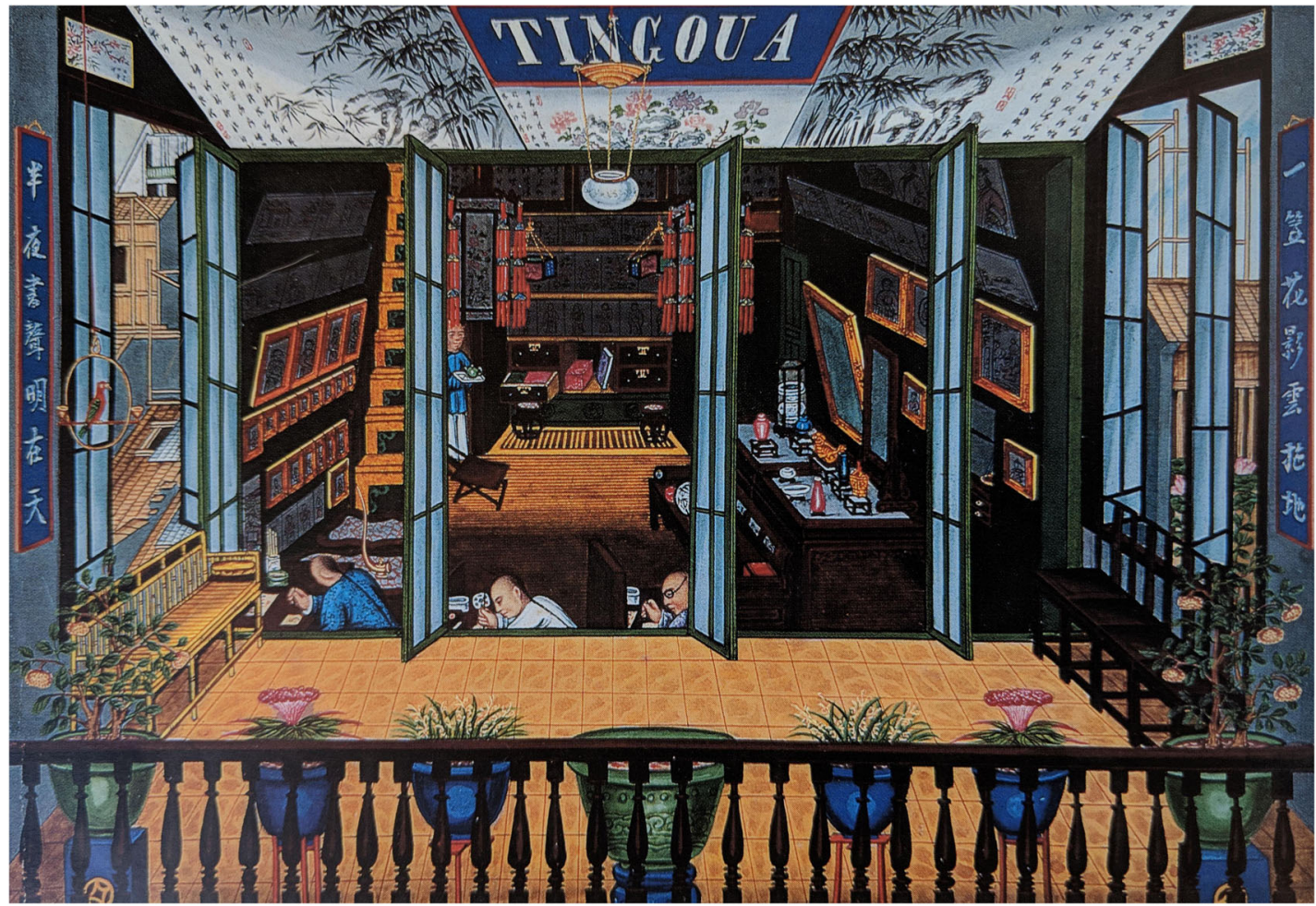

Fig. 3 Unknown artist, The Studio of Tingqua. Watercolors on paper. Private collection of Carl L. Crossman, Massachusetts. $25.4 \times 17.2 \mathrm{~cm}$.

the memoirs of Western art lovers visiting Canton. During his lifetime he even held several exhibitions at the Royal Academy in London (1835 and 1845), in France (1846), and later at other British and American institutions (Winnie, 2010). His best- known series consists of 144 oil portraits, painted in chiaroscuro, of pre-operative patients displaying large tumors or other major deformities. The series was executed in cooperation with the American missionary Peter Parker in the 1830s and 1840s. Sander 


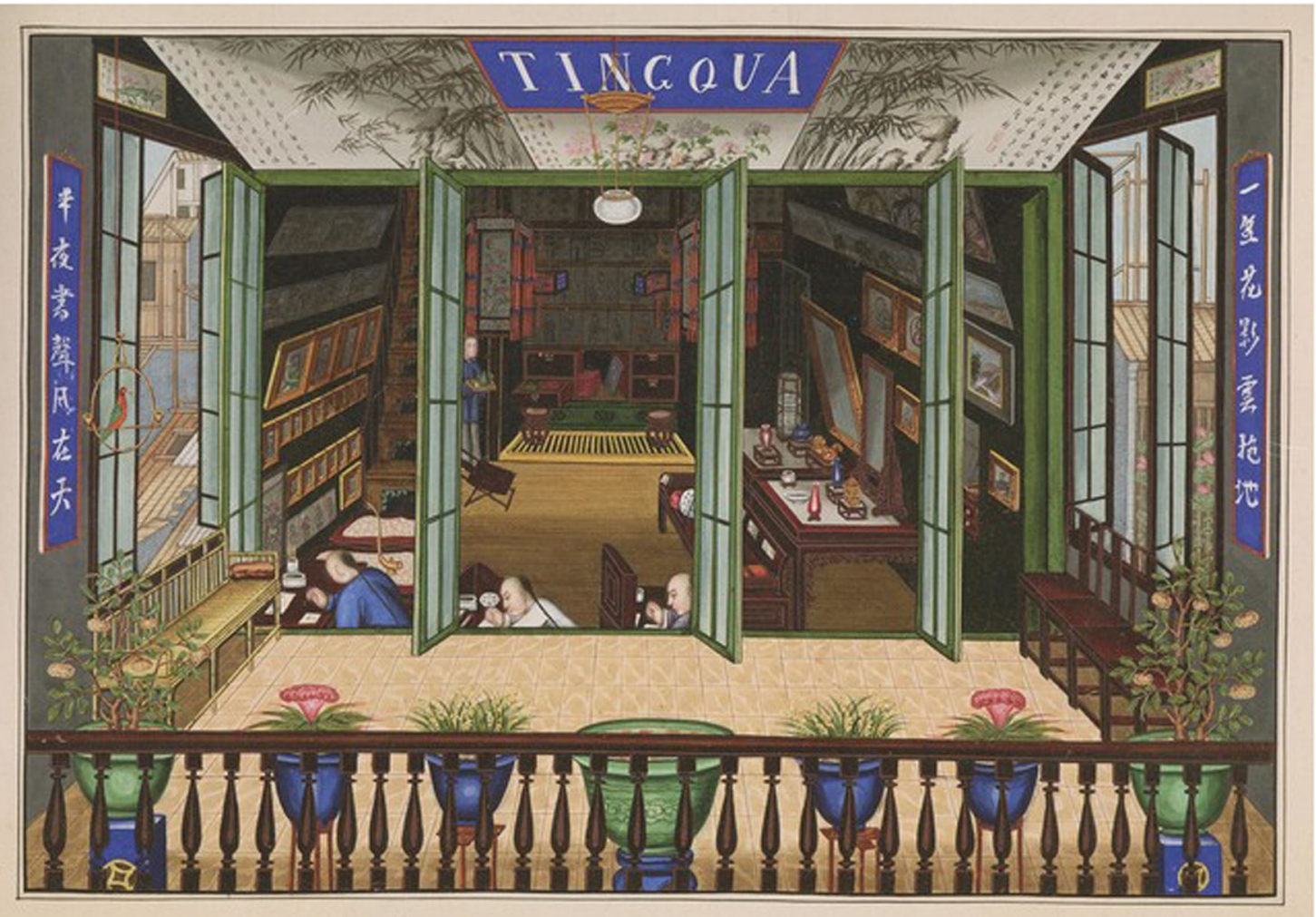

Fig. 4 Unknown artist, The Studio of Tingqua. Watercolor on paper. Privet collection of Ed Tiedemann, USA. $25 \times 17 \mathrm{~cm}$. Provenance: Acquired in 1987 from a London dealer. Later owned by The Kelton Foundation, Los Angeles.

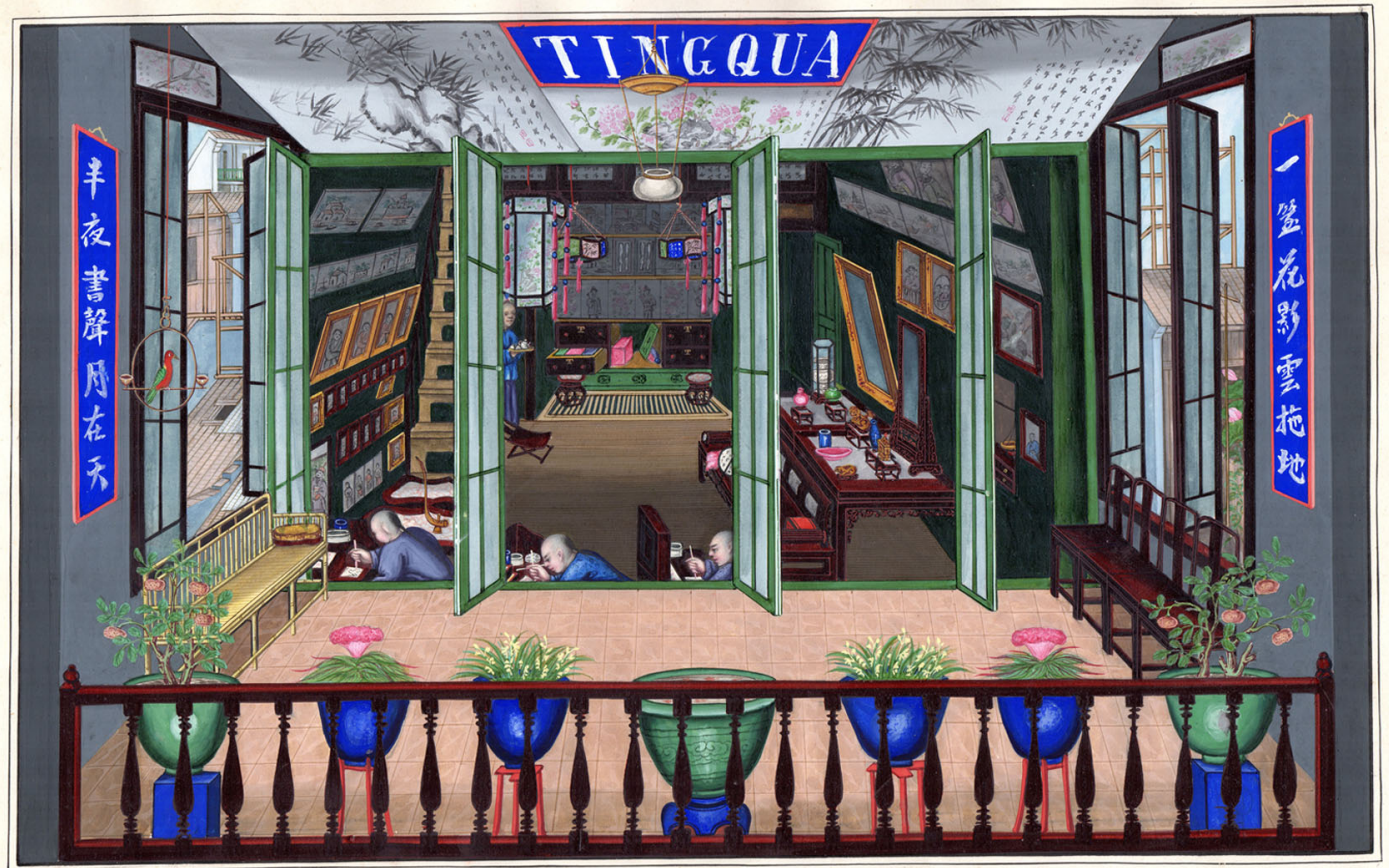

Fig. 5 Unknown artist, The Studio of Tingqua. Watercolors on paper. Independence Seaport Museum, Philadelphia. Catalog no. 1979.079. $29 \times 18 \mathrm{~cm}$. Provenance: Purchased by the museum from Childs Gallery, Boston, in 1979. Image courtesy of Independence Seaport Museum (Philadelphia, PA). 


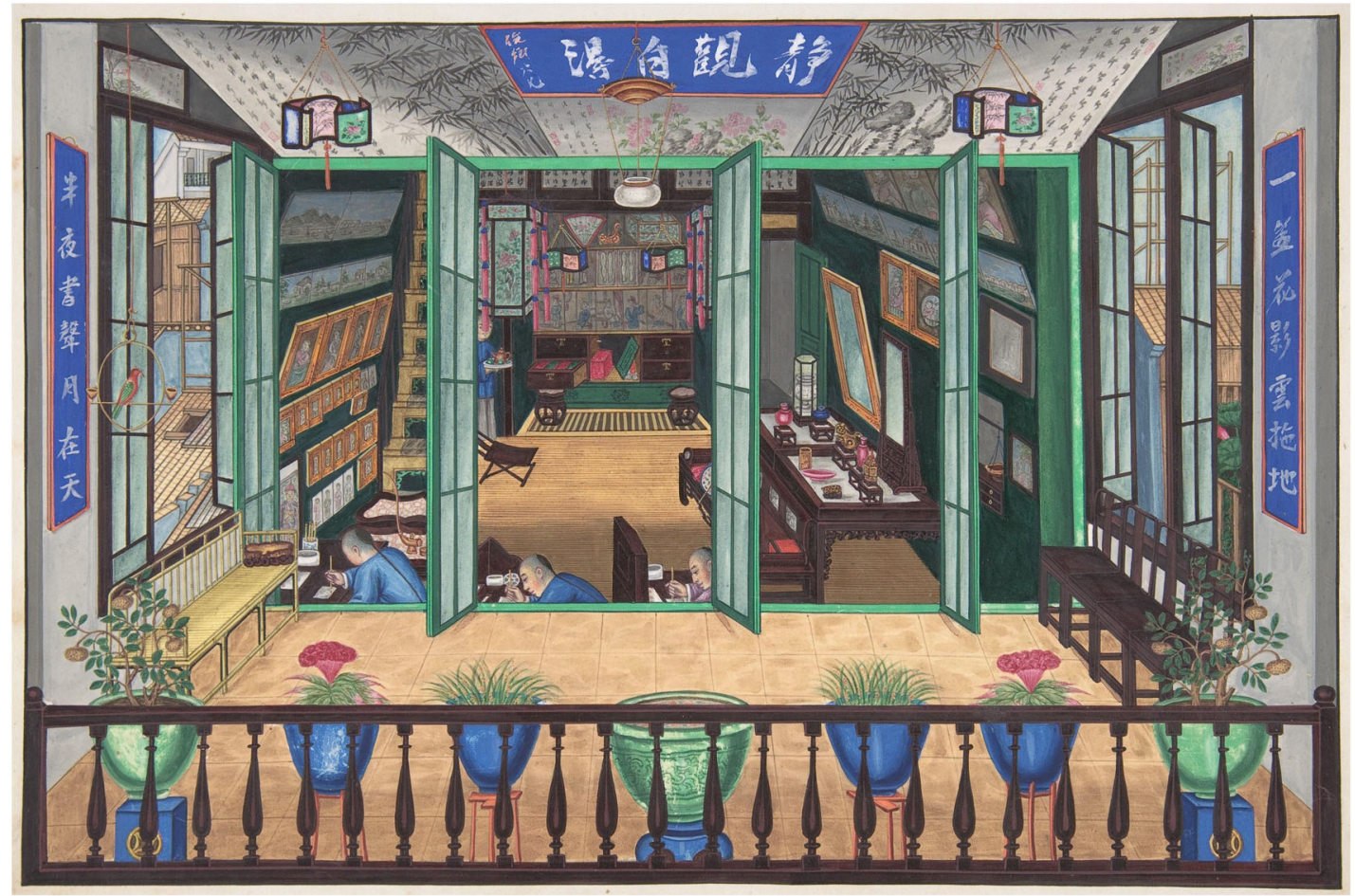

Fig. 6 Unknown artist, The Studio of Tingqua. Watercolors on paper. The Met, New York. Catalog no. 59.644.57. $26.6 \times 17.5 \mathrm{~cm}$. Provenance: Donated in 1959 by Harry G. Friedman.

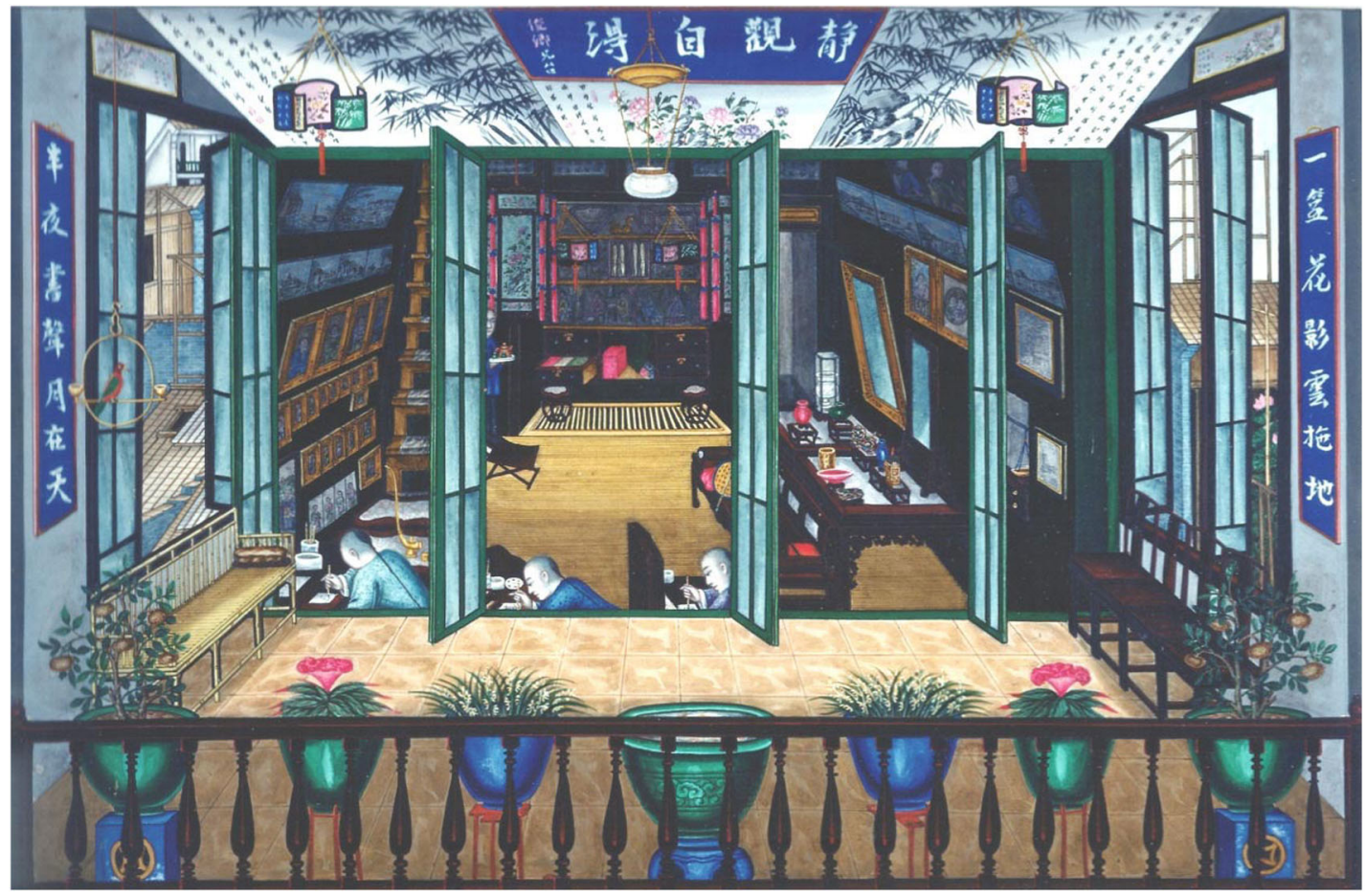

Fig. 7 Unknown artist, The Studio of Tingqua. Watercolors on paper. Private collection. Provenance: Acquired from the Martyn Gregory Gallery, London, unknown year. Photo: Martyn Gregory Gallery.

L. Gilman (1986) claims that the paintings helped Lam Qua become part of a new Chinese elite that could command Western tools, and that by using these the artist also acknowledged the weakness of Chinese traditions. This may explain why, after the First Opium War, Lam Qua chose to leave China and reopen his workshop in newly colonized Hong Kong.
Compared to his brother, who mastered the Western style and used it exclusively, Tingqua applied the same care and devotion to detail when working in a Chinese style as he did when working in a Western one. His style is rather unusual if compared to that of his colleagues in Canton. Although his paintings do fall within the Chinese Bird-and-Flower (花鸟画) genre, their subjects differ in 


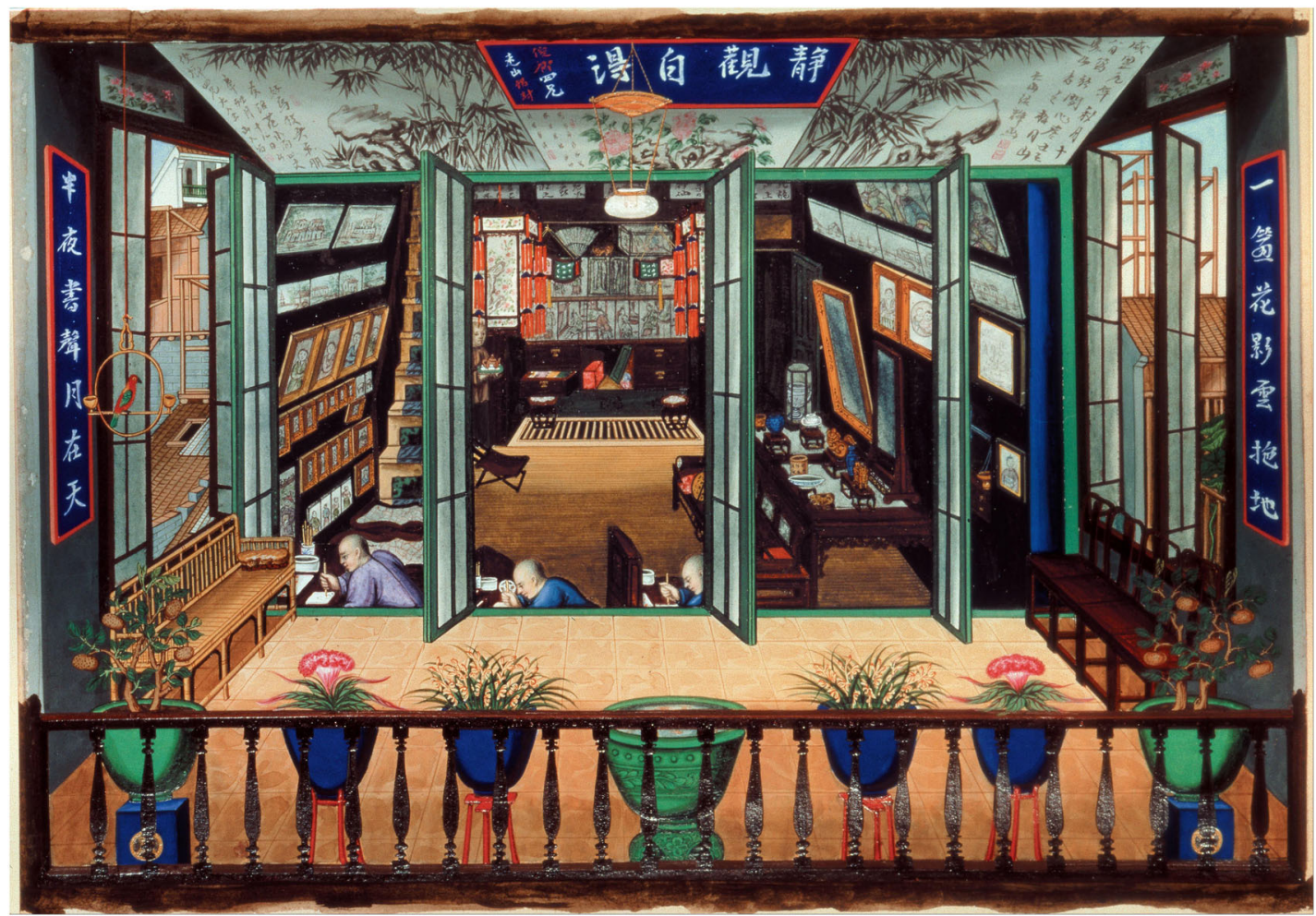

Fig. 8 Unknown artist, The Studio of Tingqua. Watercolors on paper. Hong Kong Museum of Art. Catalog no. AH1988.0012. $26.5 \times 17.5 \mathrm{~cm}$. Provenance: Acquired from the Martyn Gregory Gallery, London, in 1988. Photo supplied by the Hong Kong Museum of Art.

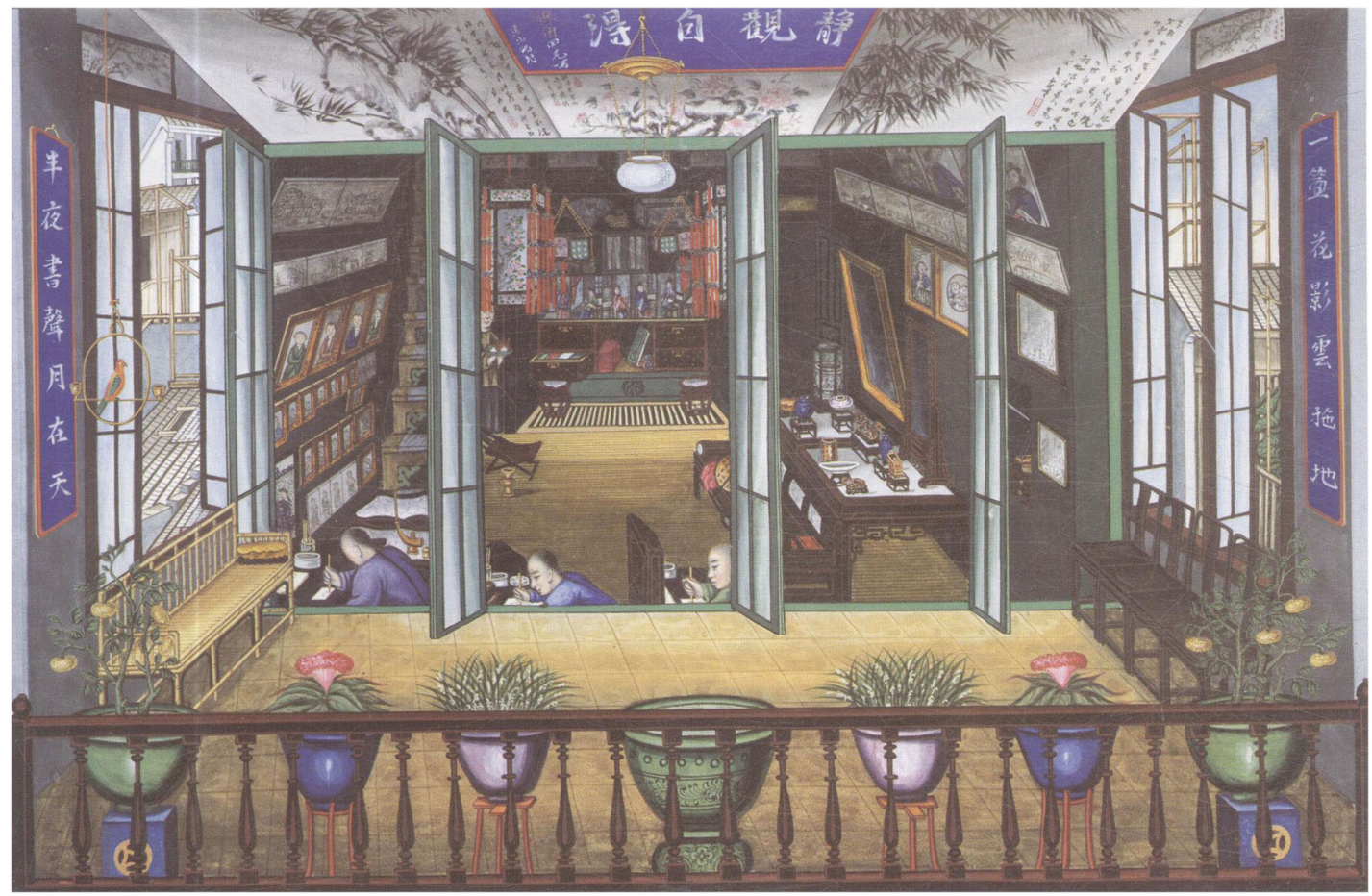

Fig. 9 Unknown artist, The Studio of Tingqua. Watercolors on paper. Sze Yuan Tang, Hong Kong. $27 \times 18 \mathrm{~cm}$.

style in that they aim at Western mimetic realism. The outcome is a pastiche that combines a Chinese style executed in watercolor with a Western one that presents volumes in three dimensions.

Most of Tingqua's career unfolded during the tense period between the two Opium Wars. In this article, I suggest that the workshop paintings can be read as self-portraits of a person living in a world witnessing a contest between two substantially different, but equally significant cultures, each struggling to prove its superiority or dominance. Among the key questions raised here are: Why did the artist plant details in the workshop paintings 


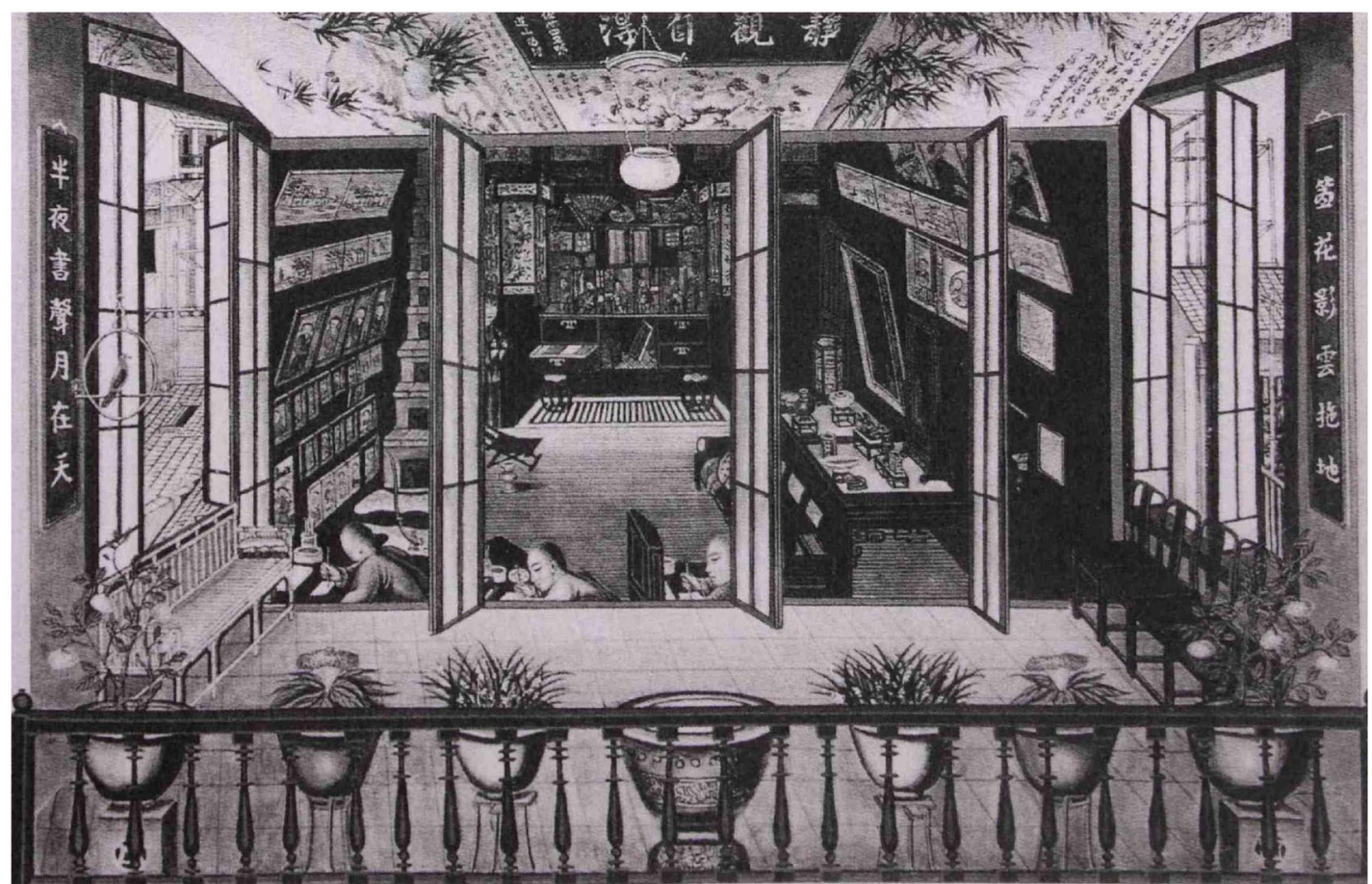

Fig. 10 Unknown artist, The Studio of Tingqua. Watercolors on paper. Private collection. Provenance: Sold by the Martyn Gregory Gallery, London, unknown year. Photo: Martyn Gregory Gallery.

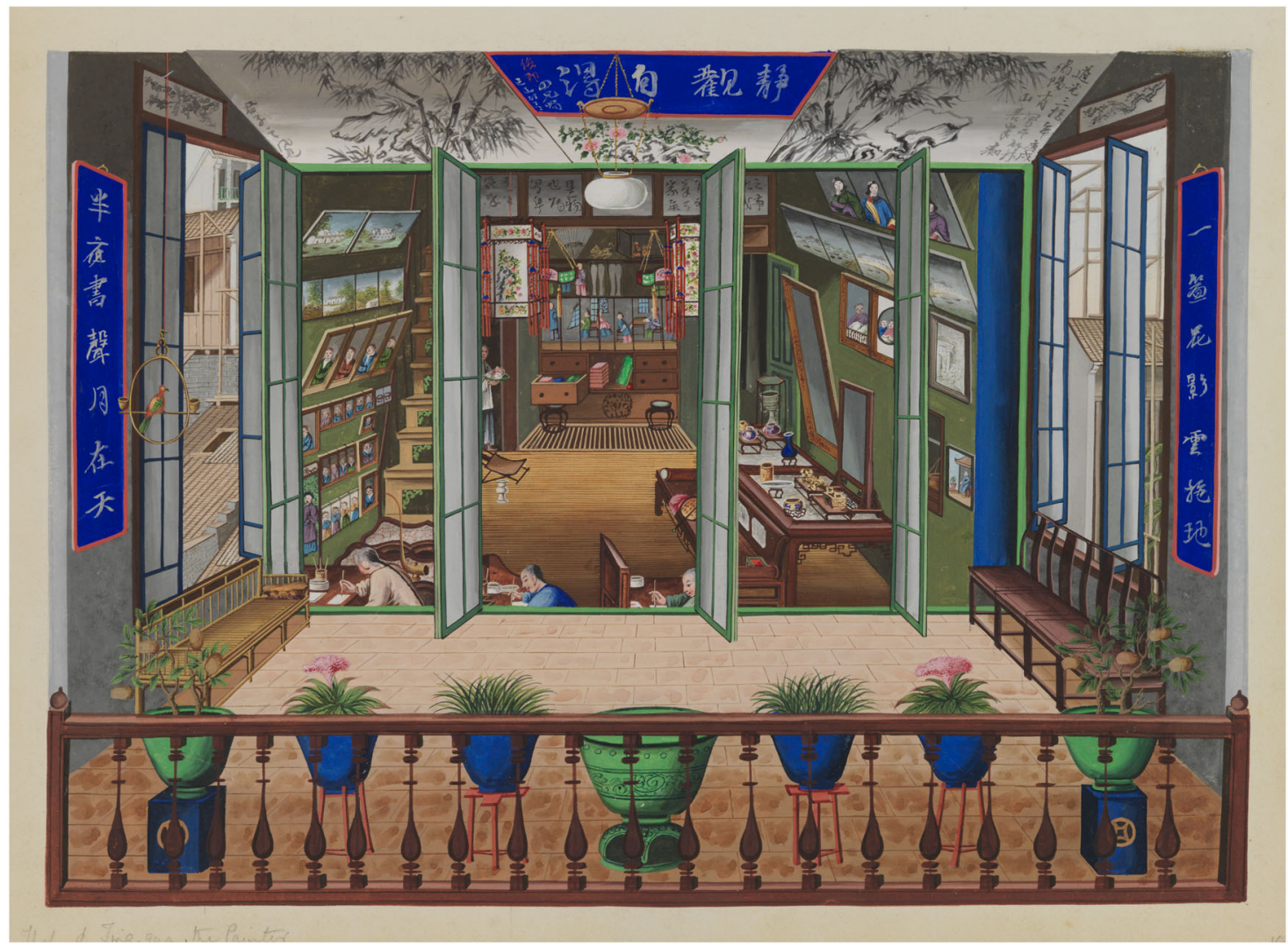

Fig. 11 Unknown artist, The Studio of Tingqua. Watercolors on paper. Peabody Essex Museum, Massachusetts. Catalog no. E83532.43. $34.9 \times 26.7 \mathrm{~cm}$. Provenance: Purchased from the estate of John Heard, 1931 (Augustine Heard and Co.) Courtesy of Peabody Essex Museum. Photo by University of Tokyo. 


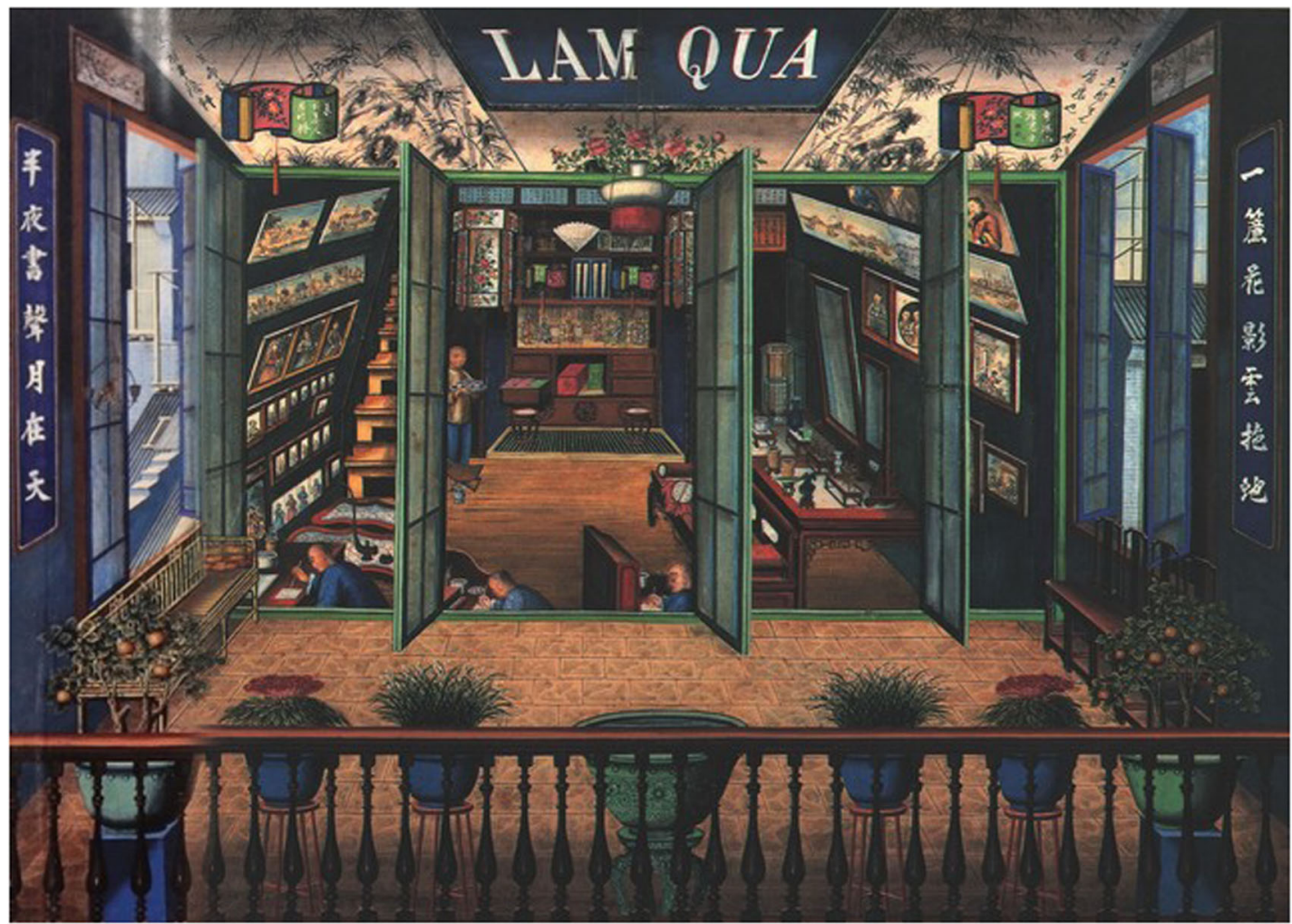

Fig. 12 Unknown artist, The Studio of Tingqua. Watercolors on paper. Private collection. Photo: Martyn Gregory Gallery.

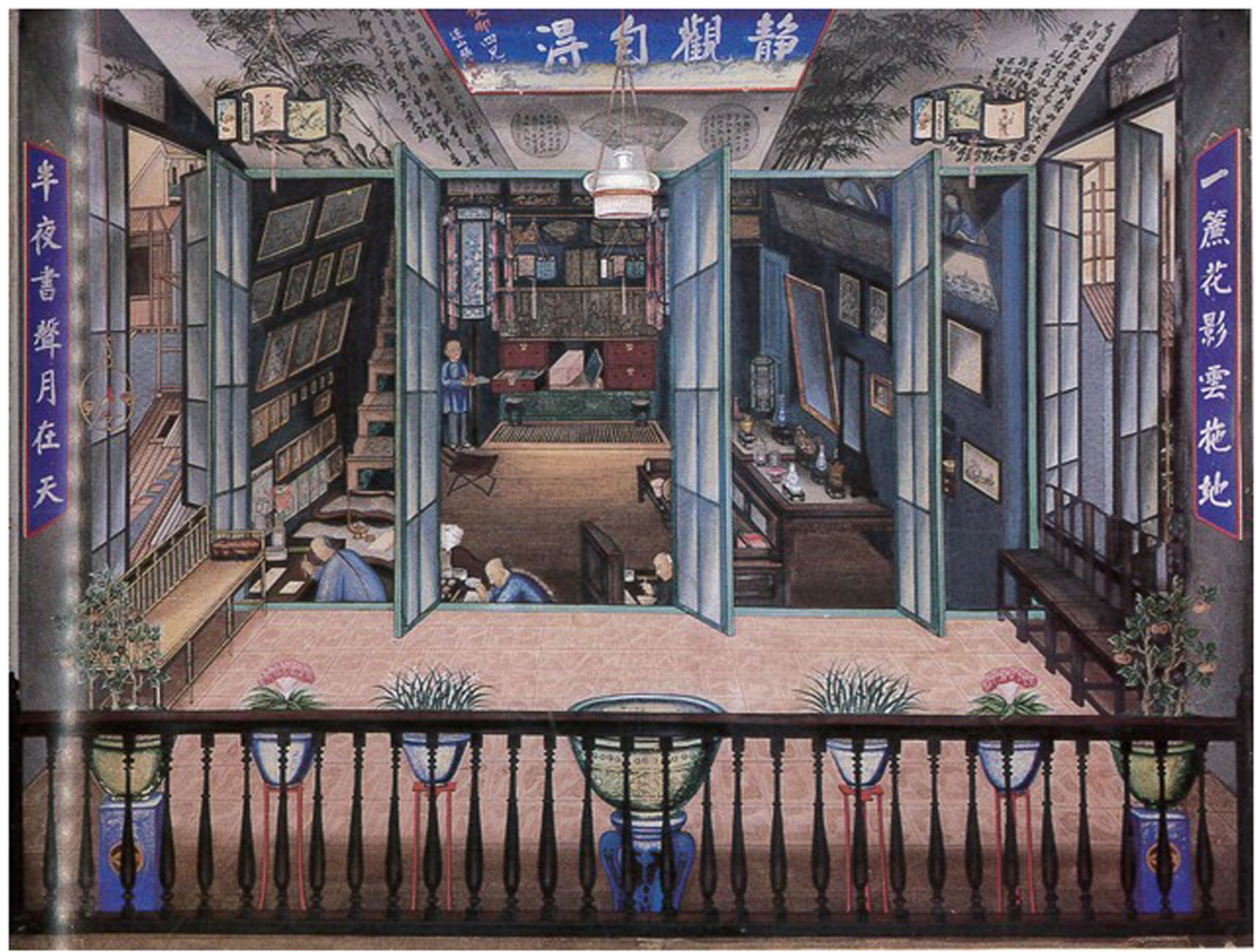

Fig. 13 Unknown artist, The Studio of Lamqua. Watercolors on paper. Private collection. $18 \times 27 \mathrm{~cm}$. Provenance: Sold by Christie's Hong Kong, 25 October 1993. Photo: Martyn Gregory Gallery. 
that would have been incomprehensible to Western viewers, the exclusive audience of these works? Should we regard these paintings as copies, originals, or something else? What can we learn from them about concepts or terms such as "copying" or "originality"? In addition, are paintings of this sort, which are usually treated as the mundane products of the China Trade industry, actually extraordinary?

The origin of the workshop paintings. In order to begin our inquiry, we need to answer three basic questions: where and when did the workshop paintings originate, and who painted them?

Tracing the provenance of the various workshop paintings is difficult. The longest available provenance history (Fig. 11) goes back only to 1931, the shortest (Fig. 1) to 1998. It is, in fact, impossible to trace any of them back to their origins in Canton, let alone to a specific workshop. Attributing dates to them is equally impossible. We do not know whether they were all products of the same studio, or even of the same artist, nor can we establish the chronological order of their production.

The identity of their creator is still in dispute. While Crossman (1972), like most scholars, attributed the workshop paintings to Tingqua, both Patrick Conner (1986) and Lee Jack Sai-Chong (2014) have suggested that they may have been made in the studio of Lam Qua. ${ }^{1}$

Five of the workshop paintings bear an inscription at the top that spells out the name "Tingqua" in Roman letters (Figs. 1-5). Based on this group of paintings, the entire series has generally been attributed to this artist's studio. Seven other paintings display a Chinese title on the top-most banner (on which I shall elaborate later), which cannot be directly related to any specific artist (Figs. 6-11, 13). Another painting contains a banner bearing the name "Lam Qua" (Fig. 12). Even if we assume this painting to be unique within the group, it reminds us that Cantonese artists copied each other's paintings. Thus, the possibility exists that the iconography originated in the younger brother's workshop and was later copied by someone in the studio of his older brother-or vice-versa. The latter possibility, however, is unlikely. Although we cannot be sure when and where the iconography originated, we know for certain that some of the versions were products of Tingqua's workshop. A number of the workshop paintings-some bearing the title in Chinese, as well as in Roman script-were found bound in albums signed by Tingqua, but none were found in albums by any other artist (Lee, 2014).

Based on the variety of the copies' style and quality, I assume that they were not all executed by the same hand, but by various artists working in Tingqua's studio, and possibly in other workshops as well. We can also see a clear difference in the handwriting present in each work. As we know from various sources, Tingqua had apprentices working for him, and some may be depicted in the paintings. It is thus possible, even probable, that they painted most of the workshop paintings.

Without a coherent provenance, we do not have enough information to date the various versions of the subject. Each collection dates its version according to its own criteria. Most reliable are the years written on the top banner in three of the paintings. The earliest of these, 1850, appears on a painting that is vastly different from the others in terms of size and style and includes an inscription in Chinese (Fig. 11). Another picture, the one bearing the name "Lam Qua" in Roman script, is dated 1851 (Fig. 12). A third, also with a Chinese inscription, is dated 1859 (Fig. 8). A fourth picture, displaying the name "Tingqua" in Roman script, contains a date that cannot be deciphered (Fig. 1). It may be that the painting dated to 1850 is not the first painting in the series. Yet if we assume that the iconography originated in
Tingqua's studio, then the earliest it could have been conceived is in 1847, the year in which the studio was founded (Lee, 2014).

A short paragraph written on the covers of three of the albums produced by Tingqua's studio (none of which includes any of the workshop paintings) informs us that the workshop was located on New China Street. ${ }^{2}$

There is much to learn from the previous short inquiry. If the workshop paintings did indeed originate in Tingqua's studio, next to the Western quarter in Canton, and the approximate period in which their iconography was devised falls between 1850 and 1861 or the two Opium Wars, then they were created amid a revolution: the beginning of China's transition towards modernization.

West meets east. What can be learned from analyzing the details of the workshop paintings? Some of their most interesting features are, in my view, those that hint at ongoing transactions between Chinese and Western traditions.

At the front of the workshop hangs a Western oil lamp, while further back are two Chinese lanterns decorated with tassels. ${ }^{3}$ The same duality of Chinese and Western artifacts and traditions can be seen in the paintings hanging on the walls of the room: in most copies, the portraits at the top right are all in a Chinese style, while those on the left (in the third row) are in a Western style. ${ }^{4}$ In fact, the entire composition can be said to exhibit this polarization: if an imaginary horizontal line running below the banner at the top of the workshop were to bisect the composition, we might view the top part as a "flat" Chinese ink painting, and the bottom as a perspectival representation of reality in the Western style.

Like much of the art made for the China trade, most versions of the workshop paintings known to us traveled to the West, and only a few remained in occupied Hong Kong (Figs. 8, 9). No copy that I know of remained in mainland China. Europeans and Americans were the prime patrons of Canton's art market, and they determined the iconography, as well as the style of the paintings that they purchased. The large sign presenting a transliteration in Roman letters-an uncommon motif in Cantonese art-which appears in six of the paintings, is one indicator of Tingqua's catering towards a Western audience. The workshop paintings offer not only clear examples of the influence of the West on China, but also evidence of the way in which some workshops in Canton adopted Western patterns of thought. One of these lies in the linear, mathematical perspective used to depict the structure of the workshop.

Like his older brother, Tingqua used the Western style on a regular basis. The paintings presenting his studio can be regarded as a type of business card through which he showcased his ability to work in the Western manner. The workshop is painted from a bird's eye view outside the balcony. This unique viewpoint allowed the artist to flaunt his skill at creating the illusion of depth or perspective and to depict the lights and shadows of the scene. Not only is the room full of various objects and figures, but the many pictures on its walls depict even more subjects that the artist can paint. This makes each painting a portfolio of the artist's skill in creating realistic paintings in a manner more typical of the West at that time.

Like his brother, Tingqua cooperated with many Western scientists. His workshop produced multiple albums depicting all sorts of unique birds, insects, flowers, etc. in a semiencyclopedism manner. These were later used by Western naturalists, ethnographers, historians, etc., to categorize the vast amount of information arriving from China. In order to make these images useful to Western scholars, the artists in Tingqua's studio had to master Western painting techniques to the point that they would be deemed accurate depictions of reality. 
As we can learn from Rosalien van der Poel's comprehensive study of paintings and photos of nineteenth-century painting workshops in Canton and Hong Kong, the iconography of these works was a common one (Poel, 2016). Yet, the workshop paintings stand out from the many others depictions of such workshops (or even other shops) in Canton during this period. Tingqua produced at least one book with sketches of other shop fronts (Tingqua c., 1850). These sorts of albums and books were popular when Tingqua began working. Copies of such an album by an anonymous artist, usually dated to 1825 , are found today in the Peabody Essex Museum. ${ }^{5}$ Unlike any of the other images of workshops and stores described above, the workshop paintings are full of details that play no part in the daily routine of the artists working in them. In almost every visual representation of a store in Canton, the place contains nothing but functional objects. Among these stores are some that sell merchandise usually regarded as prestigious, including silk, porcelain, sculptures, clocks, or even works of calligraphy.

The overloaded decor of Tingqua's workshop may have an agenda. Unlike all other professionals in Canton, Tingqua represents (and probably designed) his workplace as the space of an open-minded intellectual. The workshop's interior resembles a "cabinet of curiosities"-a room designated to present exotic "wonders" in a semi-encyclopedism manner-a phenomenon that originated in the European Renaissance and later became common in aristocratic homes (Bennett, 1995). Even if the workshop paintings were not directly influenced by this Western concept, they still show the artist as a collector of knowledge, rarity, beauty, and incredible artisanship, much of which is Western in style or origin. For example, the oil lamp at the top center of the painting-another item unusual for shops in this period-reminds us of the importance that Tingqua probably ascribed to his Western associates. Unlike other merchants in Canton, Tingqua represented himself as having a deep affiliation with the West and its people; perhaps, like his brother, he wished to be viewed as part of an aspiring new modern elite.

That being said, most of the details in these pictures are notably Chinese. Unlike his older brother, who painted in oil, Tingqua's choice of medium, watercolor, is more in keeping with the Chinese tradition. All the furniture in the scenes is made of bamboo or wood with marble insets and thus Chinese in style. ${ }^{6}$ The green vases at the front of the balcony are probably the products of the nearby Shiwan pottery workshop. ${ }^{7}$ The pots on the right and left in each painting hold a miniature kumquat tree; other pots show pink Cockscomb flowers. Both the fruits and the flowers are of Chinese origin, and both are symbols of good luck and wealth in Chinese culture. The room contains many more small objects, such as boxes, vases, and other pieces of pottery on the table. Some of the copies also show a fan and a gold Chinese sculpture of an animal on shelves in the back.

These typical China trade items would all have been well known even to an uneducated Westerner visiting Canton in this period. Their inclusion can thus be viewed as Tingqua's way of appealing to his Western consumers. Nonetheless, the workshop paintings are also imbued with details that would not have been understood by Western or even most Chinese viewers. Only Chinese literati and scholar-intellectuals would have been capable of appreciating many of these subtle references and insinuations.

For example, while some copies display the artist's Western name, "Tingqua," on the top banner of the workshop, almost all the copies known to us display a Chinese sentence (Figs. 6-11, 13). This sentence has nothing to do with the Chinese name of the artist, but is instead a chengyu (成语), a traditional Chinese idiomatic expression or aphorism, usually consisting of four characters and generally derived from ancient literature. The idiom on this banner, 得自观静, should be read from right to left and can be roughly translated as "Joy and enlightenment from quiet observation." The locus classicus of this aphorism is a poem by Chinese philosopher Cheng Hao (程影, 1032-1085). Its title is “Chance Creation of an Autumn Day" (秋日偶成), and its subject is the act of studying or meditating. The connection to Cheng Hao is confirmed by the presence beneath the quote of specific flowers-peonies-which, according to two ancient texts of Cheng Hao's period, represent his birthplace, Luoyang. ${ }^{8}$

Along with Zhu Xi, Cheng Hao and his brother Cheng Yi were the founding fathers of Lixue (理学), the official ideology of the Qing Government and part of the period's literati tradition (Shuduo and Huang, 2007). The two calligraphic texts along either edge of the painting are very typical of the period. They follow a Chinese tradition of antithetical couplets that balance each other out through their number of Chinese characters, their meaning, and tonality. The first reads "Shadows of blossoms on the curtain, clouds dragging along the ground” (一䈴花影雲拖 地), while its complement reads: "The sound of reading at midnight, the moon in the sky” (半夜書聲月在天). Although the source of the couplets is unknown, they were often reiterated in schools in order to stimulate children to study harder (Poel, 2016).

Some of the copies also contain Chinese calligraphy at the sides of the top banner, next to the sentence in the middle. Most of these too have a direct connection to the literati tradition. The banner on one version (Fig. 11) displays the sentence "The way of the junzi” (君子之道), a Chinese term often translated as "gentleman," and thus referring to those most highly cultivated in the Confucian virtues who serve as moral role models. The banner on another version (Fig. 8) presents the quote: "Lovely birds on the tree are one's good friends; falling petals on the water are pieces of poetry." This line comes from a poem entitled "The Joy of Studying in the Four Seasons," composed by Weng Shen, a literatus poet of the Song Dynasty. One painting (Fig. 13) contains a quote from a poem entitled "Painting Bamboo" by $\mathrm{Su}$ Shi (蘇軾, 1037-1101), a Chinese literatus, writer, poet, painter, and calligrapher known as one of the founders of the bamboo ink-painting tradition. ${ }^{9}$

According to literati custom, calligraphy and painting in ink (摹写) had to be learned in three hierarchical stages: by learning from the old masters (临摹), learning through the depiction of nature (写照), and finally, through the creation of mind-inspired paintings (心画). Rather than simply copying the masters, however, artists were expected to experiment and discover fundamental frames of reference for their future development (Wang, 2010; Eva, 2015). This method of imitating a master without copying his works exactly can be seen in the ink paintings within the top banner. When the artists painted motifs such as bamboo and scholar stones, they rarely copied these directly from an existent work. Unlike any other motif, the ink paintings depicted inside the banners are all unique.

Why, we may wonder, did Tingqua change ink paintings, or insert details like calligraphy and quotes by literati into paintings designed for a Western audience that could definitely not understand or appreciate them? He may have done so because the Chinese population was largely scornful of the Western style practiced by China trade painters and even of Cantonese merchants in general. In 1825, William Hunter, who visited Canton, wrote: "The occupation of a 'merchant' in China is looked down upon by wealthy land proprietors, by the literati, and by those who have risen to official rank through their own talent" (Hunter, 2015). As Chinese art scholar Mayching Kao explained, relying on the criteria of traditional painting, Chinese literati critics of Western art considered its style not that of true art: "Literal resemblance to natural objects and over-reliance on technique are the points often criticized," wrote Kao (1972). Such sentiments became ever more 
Table 1 Differences between the versions of the workshop paintings.

\begin{tabular}{|c|c|c|c|c|c|c|c|c|c|c|c|c|c|c|c|}
\hline series & number & year & $\begin{array}{l}\text { sign } \\
\text { type }\end{array}$ & $\begin{array}{l}\text { flowers } \\
\text { in } \\
\text { window }\end{array}$ & $\begin{array}{c}\text { right } \\
\text { paint } \\
\text { ing }\end{array}$ & $\begin{array}{c}\text { lamps } \\
\text { on } \\
\text { sign }\end{array}$ & $\begin{array}{l}\text { object } \\
\text { on the } \\
\text { floor }\end{array}$ & quote & fan & $\begin{array}{c}\text { left } \\
\text { painti } \\
\text { ng }\end{array}$ & $\begin{array}{c}\text { object } \\
\text { s on } \\
\text { table }\end{array}$ & $\begin{array}{l}\text { lamp } \\
\text { style }\end{array}$ & $\begin{array}{l}\text { right } \\
\text { sign }\end{array}$ & center sign & $\begin{array}{l}\text { left } \\
\text { sign }\end{array}$ \\
\hline \multicolumn{4}{|c|}{ Numbers for correlation with pic. 14} & 1 & 2 & 3 & 4 & 5 & 6 & 7 & 8 & 9 & 10 & 11 & 12 \\
\hline \multirow{4}{*}{1} & PEM 1 & & 1 & yes & yes & no & no & yes? & no & no & pink & round & flowers & English & cherries \\
\hline & $\mathrm{CLC} 3$ & & 1 & yes & yes & no & no & no & no & no & pink & round & flowers & English & cherries \\
\hline & KF 4 & & 1 & yes & yes & no & no & no & no & no & pink & round & flowers & English & flowers \\
\hline & PSM 5 & & 3 & yes & no & no & no & no & no & yes & pink & round & cherries & English & cherries \\
\hline 2 & MET 6 & & 4 & yes & no & yes & no & no & yes & yes & pink & round & flowers & 六 Chinese & cherries \\
\hline \multirow{3}{*}{3} & HKAM 8 & 1859 & 2 & no & no & no & no & yes & yes & yes & white & $\begin{array}{c}\text { straigh } \\
t\end{array}$ & flowers & 四 Chinese & flowers \\
\hline & SYT 9 & & 3 & no & no & no & yes & yes? & yes & yes & white & $\begin{array}{c}\text { straigh } \\
t\end{array}$ & cherries & 四 Chinese & cherries \\
\hline & 10 & & 3 & no & no & no & yes & yes? & yes & yes & white & round & cherries & Chinese 四 & cherries \\
\hline \multirow[b]{2}{*}{4} & PEM 11 & 1850 & 2 & no & no & no & yes & yes & yes & yes & white & $\begin{array}{c}\text { straigh } \\
t\end{array}$ & cherries & 四 Chinese & flowers \\
\hline & LAM 12 & 1851 & 5 & no & no & yes & yes & yes & yes & yes & $\begin{array}{c}\text { differe } \\
\text { nt }\end{array}$ & $\begin{array}{c}\text { differe } \\
\text { nt }\end{array}$ & cherries & LAM & cherries \\
\hline
\end{tabular}

ingrained between the two Opium Wars, when those who cooperated with Westerners would have been regarded as traitors of the Empire (Chu, 2008). The opium pipe in nearly all the workshop paintings (save Fig. 8) is a reminder of this period. One may therefore posit that when he presented himself and his workshop, Tingqua underscored the fact that despite painting in the Western manner, he was still loyal to the Chinese tradition. Moreover, this is how he could have demonstrated to his literati colleagues that he knew Chinese culture according to their own standards, and indicated to them that he was not simply a copyist learning how to draw, but an artist who could paint mind-inspired pictures as had the supreme ones of the past.

Compared to his brother, who mastered the Western style and used it exclusively, Tingqua painted in the Chinese style with the same care and devotion to detail as he did when working in the Western one. In the workshop paintings, the two cultures are manifest in the two different methods of representation that he nonetheless used with equal care.

Spotting the differences. When executing the ink paintings and calligraphy on the banner, Tingqua (or the assistants in his workshop) created variations. Based on our knowledge of the Chinese tradition of imitation, we may speculate that he did so to demonstrate his mastery of the brush to the Chinese literati. Meanwhile, when painting the interior of the workshop and creating a souvenir for Western visitors to Canton, he chose to stick to Western traditions. He copied the paintings in a stricter manner and concentrated on creating the illusion of depth, proving to potential customers that he could easily adjust to the style typical of the West, and thus meet their preferences and expectations. This was an important task for a studio used by Western scientists, who had to be sure it produced valid depictions of reality.

These two profoundly different methods of copying-one grounded in the Chinese tradition, the other in the Western tradition-are found in all the versions of the workshop paintings. Furthermore, if we were to explore these qualities in each painting individually, we would notice pronounced variations in the extent to which each painting tends towards one or the other. For example, several copies show greater similarity to each other (e.g., Figs. 1 and 4, and Figs. 9 and 10 are almost identical), while some display a distinct identity (e.g., Figs. 11-13 are all unique).

When we examine the text in the paintings, the tension between the Eastern and Western traditions of imitation becomes even sharper. While some paintings contain a quote from a literatus on the top banner (e.g., Figs. 8, 11-13), others present not a real text but a pseudo-text, a scribble that looks like Chinese characters that is actually the mimetic illusion of text (e.g., Figs. 3-7). ${ }^{10}$

There are many other small differences between the versions that would seem negligible to an untrained eye. Many of these are listed in Table 1 and Fig. 14. In the table, I have divided the paintings into four distinct groups. We can thus see how some paintings share a specific characteristic, such as the presence of flowers in the window, a fan on the shelf at the back of the room, the language of the sign at the top of the painting, or the existence of a Chinese quote on this sign. In the table, each group is presented in a different color, as are the different styles of the Chinese painting at the top of the room. Questions with a binary answer are coded red or green, and specific changes in the different sets of paintings are coded in different colors.

When all these differences are presented side by side, a pattern begins to emerge. On the one hand, we find paintings closer to the Eastern tradition: paintings with a distinct identity. Almost every detail in these paintings is depicted differently. The connection of these to the Chinese tradition goes beyond the copying method: most of them display a Chinese title on the top banner and a unique quote from a literatus. Most of the dated paintings belong to this group. It is therefore probable that these were created earlier. On the other hand, some paintings are closer to the Western tradition of imitation; they are largely similar to each other. Most of them display an English title, and most contain no real Chinese quote but only a scribbled text. Today, most of these are in the United States. They seem to have been painted more quickly and with less attention to detail, probably for commercial reasons. ${ }^{11}$

We may imagine an axis: at one pole are those paintings leaning towards the Western tradition of imitation, and at the other, those leaning towards the Eastern tradition. Based on this axis, we may examine the duality of these paintings, which not only incorporate Eastern and Western traditions and contradictions, but also represent tensions along a timeline. 


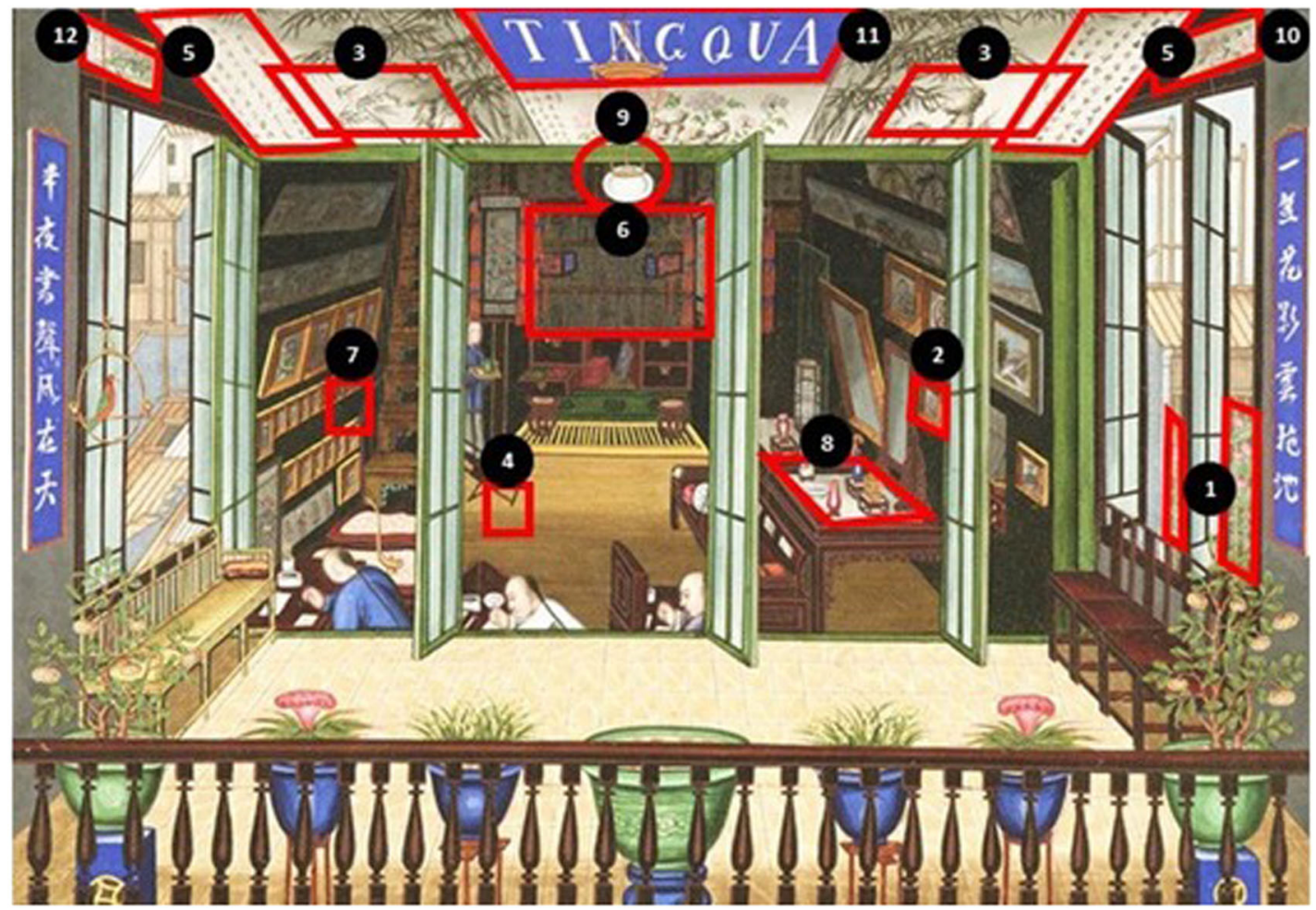

Fig. 14 Differences between the versions of the workshop paintings. See correlating numbers in Table 1.

\section{Conclusions}

The iconography of the workshop paintings originated at the intersection of a particular time and space: between the two Opium Wars, and next to the Western quarter in Canton. This was the time and place that saw the beginning of China's process towards modernization, one that abounded with tension between China and the West. The artists who executed the workshop paintings made a great effort to express both their abilities and capabilities in these two different painting styles, and their knowledge of the defining attributes of each of them. This EastWest polarity is also visible in the differences between the iconographical variations of the workshop paintings: while some paintings lean more towards the Eastern traditions, others are directed at the West.

Like the entire "art-world" of Canton, these paintings rely on the Western, as well as Eastern traditions to come up with a new, homogeneous style. By using watercolor, the artist was able to paint the realistic painting of the workshop and the calligraphy at the top in the same medium. The use of this medium ensured that the paintings of the workshop bore some of the stylistic attributes of traditional Chinese painting. At the same time, the banner at the top of the room, which displays a Chinese ink painting and quotes by literati, reveals a surprising attribute of traditional Western art: it is tilted slightly backwards. The calligraphic paintings-like the room itself-are presented in three-dimensions.

The workshop paintings offer but one case of the abounding tensions that characterized China in the mid-nineteenth century. They point to far more than a particular painting workshop. The iconography of the studio captures the cultural encounter between two momentous, distinct cultural entities, each holding different worldviews and a different set of values and norms regarding art.

The workshop paintings may teach us that some of the artists in Canton had aspirations that rose beyond making agreeable paintings for their paying customers. Further research may teach us the degree to which the Chinese population itself was an audience for Canton's export art. There were, of course, Chinese viewers who lived in and around the Western quarter in Canton, but did those commoners actually understand the references to literati and the insinuations in the paintings of the studio? Or, was Tingqua trying to fashion himself a literati artist for his own sake, with no regard for the commoners?

By asking and answering such questions, researchers of Canton's "art-world" could start to construct a more complete picture of the local aspects of globalism that affected Canton in this period. This kind of approach may also prove useful to a more precise understanding of the multiculturalism embodied in many of Canton's products.

The workshop paintings can thus be read as self-portraits of a person living in a world observing the rivalry between two substantially different cultural traditions, each struggling to prove its superiority or dominance. Attesting to the old world he was part of altering, the artist decided to treasure some of its features in works whose patrons would not be expected to find them.

One of the reasons the workshop paintings are so extraordinary is that in addition to conveying a personal journey, they also serve as rare visual testimony of the tensions and contradictions within Canton's art world between the two Opium Wars. These paintings may teach us about Tingqua, as well as other Cantonese artists and residents, and their abilities to grasp the complexity of both cultures and bridge the gap between them. The multiplicity of the iconography and the minor changes between the versions may help us see and understand the delicate relations perceptible in this environment-between East and West, copying and originality, and two different traditions-all appearing side by side on the same artistic surface.

\section{Data availability}

All data generated or analyzed during this study are included in this published article. 
Received: 24 May 2020; Accepted: 30 September 2020;

Published online: 23 October 2020

\section{Notes}

1 Lee Jack Sai-Chong (2014) tried unsuccessfully to identify the artist who created them based on the fact that the name "Junqing" is inscribed on some of the paintings.

2 The workshop moved three times along that street over the years, occupying the buildings at Number 12 (in 1847), 15 (1851), and 16 (1854) (Lee, 2014). I propose that the paintings depict the workshop when it was at 12 or 15 rather than $16 \mathrm{New}$ China Street, as many researchers have claimed, because Tingqua moved to this studio too late for the first dated copies to be created there.

3 In four of the paintings, lanterns also cover part of the top banner (Figs. 6, 7, 12, 13).

4 Patrick Conner (1986) has identified some of the Chinese landscapes hanging on the walls of the workshop as views of Guangzhou and Hong Kong.

5 Due to some similarity in style and content to the workshop paintings, some researchers have mistakenly attributed these works to Tingqua, even though they date far too early to be by him.

6 Crossman (1972) noticed that the bamboo settee at the left side of the balcony is similar to those exported to the West. The pictures are thus a testimony to the fact that the settees were also made for local consumption by the residents of Canton.

7 Personal communication with Marcus de Chevrieux, 2016.

8 In "On the Love of the Lotus," Zhou Dun Yi (1017-1073) writes: "Since the Tang Dynasty, all people have deeply loved peonies." Ouyang Xiu (1007-1072) devoted an entire text to the connection between these flowers and this town: "Seduction by Flowers: Ouyang Xiu's Record of the Peonies of Luoyang."

9 The full words of this quote are: 子瞻归自道场何山, 遇大风雨, 因覣耘老溪亭, 命 官奴秉烛捧砚, 写风雨竹-枝, 题诗云: 更将掀舞势, 把烛书风篌。美人为破颜, 恰 似腰肢蜄] It can be roughly translated as: "Returning from the Dojo, on the Holy mountain, in the wind and the rain, to rest in his cabin by the river weeds, he ordered his slave to hold a candle, put his pen to a branch of windswept, wet bamboo, and wrote the poem: Multitudes uplifted to dance they throng/Hold the candle, my windswept bamboo is song/All beauty is broken, like a fractured limb/Or a waist, or a face, with no countenance."

10 In four of the paintings (Figs. 1, 2, 9, and 10), there may be a text that only a notable expert in Caoshu-calligraphy could read. However, the experts I contacted said they could not read it.

11 One painting in the series (Fig. 3) is very peculiar. This copy is probably the most famous of them all as it is in the private collection of the well-known China-trade scholar Crossman. It was published in his book (Crossman, 1972) and has since appeared in many sources. Nonetheless, it contains at least three odd features, which to my knowledge, no study has yet considered: (1) the most noticeable one is the artist wearing glasses at the front of the shop; (2) the name of the artist on the top banner is misspelled-the letter "Q" appears as an "O"; (3) the Chinese antithetical couplets at the sides of the painting also contain a mistake, as the character 月 (moon) appears in them as 明 (bright). I do not know how to explain all these deviations.

\section{References}

Bennett T (1995) The birth of the museum: history, theory, politics. Routledge, London

Cody WJ, Terpak F (eds) (2011) Brush and shutter: early photography in China. Getty Publications, Los Angeles

Conner P (1986) The China Trade, 1600-1860. Royal Pavilion. Art Gallery and Museums, Brighton

Conner P (2013) Paintings of the China trade: the Sze Yuan Tang collection of historic paintings. Hong Kong Maritime Museum

Chrisman CSM (1984) Adventurous pursuits: Americans and the China trade. Smithsonian Institution Press, Washington, pp 1784-1844

Chu IP (2008) Crossing the borders of a merchant class: imaging and representing elite status in the portraits of the Hong merchants of Canton. Dissertation. University of British Columbia, pp. 49

Crossman CL (1972) The China trade. Pyne Press, New Jersey, pp 255-256. pp 9, 19
Eva KWM (2015) Influence of global aesthetics on Chinese aesthetics: the adaptation of moxie and the case of Dafen Cun. Issues of contemporary art and aesthetics in Chinese context. pp. 95-103

Fan F (2004) British naturalists in Qing China: science, empire, and cultural encounter. Harvard University Press, Harvard, p. 40

Farris J (2007) Thirteen factories of Canton: an architecture of Sino-western collaboration and confrontation. Build Landsc 14(1):79

Gilman SL (1986) Lam Qua and the development of a westernized medical iconography in China. Med Hist 30(1):66-67

Hunter WC (2015) The 'Fan Kwae' at Canton before treaty days, 1825-1844. Franklin Classics Trade Press (2018) p. 23

Lee SCJ (2014) China Trade Painting 1750s to 1880s. Sun Yat-sen University Press, Hong Kong, p. 174, 179, 187

Mayching (1972) China"s response to the west in art: 1898-1937. Dissertation, Stanford University

Poel RHM (2016) Made for trade-Made in China. Chinese export paintings in Dutch collections: art and commodity. Dissertation, Leiden University. pp. 73-74, pp. 76-95

Shuduo G, Huang D (2007) Characteristics of lixue in Qing dynasty. Front Philos China 2(1):1-24

Tingqua (c. 1850) 144 Dessins Relatifs à l'Industrie de la Soie en Chine. http:// cnum.cnam.fr/CGI/redirv.cgi?MS49 Accessed 23 May 2020

Wang K (2010) The platonic mimesis and the Chinese moxie. Int Yearbook Aesthet 14:214-233

Wing Chong RL (ed) (2011) Artistic inclusion of the east and west. The Leisure and Culture Services Department, Hong Kong

Winnie WYW (2010) After the copy. Dissertation, MIT Press, Cambridge, p. 79

\section{Acknowledgements}

The author is grateful to the Mandel Scholion Interdisciplinary Research Center in Humanities and Jewish Studies at the Hebrew University of Jerusalem for its kind support of this publication. The author also wishes to thank the museums and galleries that helped collect the workshop paintings and present them freely to the public, and to the curators who shared their knowledge. A special thanks is reserved for Patrick Conner and the Martyn Gregory Gallery. Finally, a special thanks go to Clara Pan and Lina Wang for their translations and elucidation of Chinese culture.

\section{Competing interests}

The author declares no competing interests.

\section{Additional information}

Correspondence and requests for materials should be addressed to E.Y.

\section{Reprints and permission information is available at http://www.nature.com/reprints}

Publisher's note Springer Nature remains neutral with regard to jurisdictional claims in published maps and institutional affiliations.

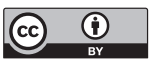

Open Access This article is licensed under a Creative Commons Attribution 4.0 International License, which permits use, sharing, adaptation, distribution and reproduction in any medium or format, as long as you give appropriate credit to the original author(s) and the source, provide a link to the Creative Commons license, and indicate if changes were made. The images or other third party material in this article are included in the article's Creative Commons license, unless indicated otherwise in a credit line to the material. If material is not included in the article's Creative Commons license and your intended use is not permitted by statutory regulation or exceeds the permitted use, you will need to obtain permission directly from the copyright holder. To view a copy of this license, visit http://creativecommons.org/ licenses/by/4.0/.

(C) The Author(s) 2020 